\title{
Where's the Variation? Variance Components in Tooth Sizes of the Permanent Dentition
}

\author{
Edward F. Harris* \\ Department of Orthodontics, The Health Science Center, University of Tennessee 38163
}

ABSTRACT Studies have shown that there are only a few canonical axes of tooth size variation in the permanent dentition. Despite the numerous measurements that might be taken (e.g., crown length and breadth of 32 teeth $=64$ variables), most of the canonical structure is explained by 3 or 4 overarching axes of variation. This study used maximum likelihood components of variance analysis to determine where the major sources of statistical variation are among the crown dimensions in the permanent dentition. Mesiodistal and buccolingual crown dimensions were measured on all permanent teeth (excluding M3s and averaging sides) in 100 American whites and 100 American blacks, evenly divided by sex. The SAS program varcomp estimated the sources of variation across 7 aspects of the dentition, namely race, sex, arcade, tooth (incisor, canine, premolar, molar), position (mesial, distal), dimension (MD, BL), and a residual term. Most variation is shared; residual variance was just $21.8 \%$ of the total. Considering the six components

If one measures the conventional mesiodistal and buccolingual crown diameters of the 32 permanent teeth in the human dentition, there are 64 variables, which is comparable to an extensive battery of craniometrics or anthropometrics (e.g., Davenport, 1927; Martin, 1928). One might suppose that there is a lot of statistical information - several axes of variation - in the odontometrics based on tooth types, side, arcade, a tooth's position in its morphogenetic field, sex, race, and so on. However, the morphological and statistical redundancy among tooth types has long been recognized, and this redundancy sharply diminishes the information content of batteries of crown dimensions. Bateson (1894) included teeth in his anatomic examples of meristic series that included phalanges, vertebrae, and ribs. This phenomenon of multiple analogous skeletodental units that develop clinally along a growth axis also is termed polyisomerism (Gregory, 1934). The supposition is that the shared morphologies are controlled by common control mechanisms (genes, gene products), but verification has only recently been provided (e.g., Yamaguchi, 1997; Green, 2002). Weiss (1990), Jernvall (2000; Jernvall and Jung, 2000; Jernvall and Thesleff, 2000), and others suggest that polyisomerism is a conservative, efficient mechanism for increasing (or, occasionally, decreasing) the anatomic units, which is more obvious phylogenetically, but occurs ontogenetically as well. The "several" of shared variance, the greatest $(82.8 \%)$ was due to tooth type (I, C, P, M). In contrast, only $4.9 \%$ was attributable to the black-white race difference, which confirms results of other biological data that the preponderance of variation is within groups, not among them. More striking is the lack of variation between males and females $(1.2 \%)$-confirming the insensitivity of tooth crown dimensions for forensic purposes. Very little shared variance $(0.6 \%)$ was due to tooth position, indicating that the mesial "pole" tooth that is metrically and morphologically more stable does not possess much more informational content statistically. Whether the tooth was maxillary or mandibular accounted for $6.9 \%$. In a practical sense, the large variance due to tooth type implies that dental anthropologists commonly will want to include variables from all tooth types (I, C, P, M) rather than multiple measurements within a tooth type, since tooth type is the canonical axis of variation. Dental Anthropology 2003;16(3):84-94.

canonical axes of variation expected from a battery of tooth dimensions do not actually occur because tooth crown dimensions are invariably positively intercorrelated (e.g., Moorrees and Reed, 1964; Potter et al., 1968; Henderson, 1975; Townsend, 1976; Harris and Bailit, 1988).

Genetic covariance among continuous-scale variates like crown dimensions arises from pleiotropic effects of the contributing genes (e.g., Falconer, 1989). Indeed, the principal theme of Butler's seminal studies of morphogenetic fields $(1939,1956,2001)$ is the developmental dependencies (covariance) of tooth morphologies and dimensions of teeth within the three major fields in mammals, namely incisors, canines, and postcanine tooth types. The consequences for the dental anthropologist are that much of the informational content of many tooth crown dimensions are statistically redundant. Measuring more teeth or measuring more dimensions of the same teeth does not proportionately increase

A version of this paper was presented at the Annual Meeting of the American Association of Physical Anthropologists, Tempe, AZ, 2003.

\footnotetext{
*Correspondence to: Edward F. Harris, Department of Orthodontics, The Health Science Center, University of Tennessee, Memphis 38163. E-mail eharris@utmem.edu
} 
the researcher's ability to discriminate between sexes, or populations, or races, or species. Falk and Corruccini (1982) have shown this quite simply: the discriminatory power among groups was much better using craniometric variables (with less covariance among traits; Solow, 1966) than an equivalent battery of tooth crown dimensions.

\section{MATERIALS AND METHODS}

The data analyzed here consist of maximum mesiodistal (MD) and buccolingual (BL) tooth crown dimensions of all 14 permanent tooth types, omitting M3s. Measurements were made on the full-mouth dental casts of 100 American whites and 100 American blacks using electronic-readout sliding calipers with the beaks machined to fit well into the embrasures between teeth. Measurement technique followed that described by Selmer-Olson (1949). There was an equal number of males and females in each race, and the subjects were contemporary American adolescents with all 28 teeth fully erupted without any restorations that would affect the measurements. Teeth on just one side of the mouth were measured (either left or right, on an individual basis), but numerous studies have shown that the variance attributable to side is meager and due to just bilateral asymmetry plus technical error and may safely be ignored without biasing the other effects (e.g., Lundström, 1948; Potter and Nance, 1976).

\section{Statistical analysis}

It is implausible from what is known about odontometrics (e.g., Kieser, 1990; Hillson, 1996) to suppose that either genetic or environmental variation in tooth size is distributed across the dentition in even a vaguely uniform manner. Instead, some of the axes of variation will account for appreciably more than other sources of variation. Six axes of variation were estimated in the present study. Variation was compared by (1) race, (2) sex, (3) arcade (maxilla or mandible), (4) tooth type (incisors, canines, premolars, and molars), (5) dimension (mesiodistal versus buccolingual crown diameters), and (6) position (the mesial or distal tooth within a morphogenetic field).

To find out how the variance in tooth size is apportioned across these six axes, model II, maximum-likelihood estimates of variance components were estimated (Hartley et al., 1978) using the SAS procedure varcomp (SAS, 1989).

Two "races" were contrasted, American blacks and whites, but the perspective is to view these as random samples from the "universe" of possible races (e.g., Coon, 1965). Similarly, any number of crown dimensions could be measured on a tooth (cf. Corruccini, 1977, 1978; Black, 1979; FitzGerald and Hillson, 2002), the conventional two assessed here (i.e., the standard MD and BL dimensions) are best viewed as a sample of two picked from a population of dimensional possibilities.

\section{RESULTS AND DISCUSSION}

\section{Multivariate analysis}

Most of the total variance for odontometrics is shared (common) rather than unique variance. This has long been recognized (e.g., Garn et al., 1965, 1968; Moorrees and Reed, 1964) insofar as all MD and BL crown dimensions are positively intercorrelated with one another throughout the dentition. This is true for the present data set (Table 1) where every one of the 378 pairwise comparisons is positively and significantly correlated at $P<0.001$ ( $n=200$ for each comparison). This means that "size" is a pervasive controlling factor throughout the dentition. It also means that (1) tooth size can be predicted with some accuracy from other tooth sizes (e.g., Moyers, 1988; Tanaka and Johnston, 1974) but that (2) since all dimensions are intercorrelated, they all tend to estimate the same thing (namely "overall size") rather than carrying unique, nonredundant information. Developmentally, these statistical intercorrelations appear to reflect the communalities of a few rather than many axes of ontogenetic control (Weiss, 1990; Salazar-Ciudad and Jernvall, 2002).

Statistical redundancy also has been illustrated in the several studies of human tooth size using factor analysis (e.g., Potter et al., 1968; Harris and Bailit, 1988). For the present data, there are just three orthogonal axes of shared variation among the 28 crown dimensions, with "overall size" accounting for most (83\%) of this (Fig. 1). The other two axes of variation are (1) BL breadths of the anterior teeth contrasted with MD lengths of the cheek teeth (premolars and molars), accounting for $10 \%$ of the shared variation, and (2) MD lengths of the incisors contrasted with BL breadths of the posterior teeth (canines, premolars and molars) accounting for $7 \%$. Collectively, these three axes of shared variation (i.e., variation not unique to a single crown dimension) is $73 \%$ of the total variation.

PCA has been performed across a broad range of human samples, showing concordant results and, thus, the nature of the covariance matrices probably is essentially independent of the population under study. It is obvious that these three canonical axes of metric control of the dentition are far fewer than the 28 variables measured for the dentition, and this "reduction" is due to statistical (and developmental) redundancy among crown sizes.

\section{Variance components}

Results from the SAS program varcomp disclosed that, taking total variance as $100 \%$, the shared variance accounted for by the six variables in the model was $79.2 \%$ while the residual variance, unique to individual measurements accounted for the other 21.8\% (Fig. 2). This is about a four-to-one ratio of explained to residual variances, suggesting that the six factors listed above do, 


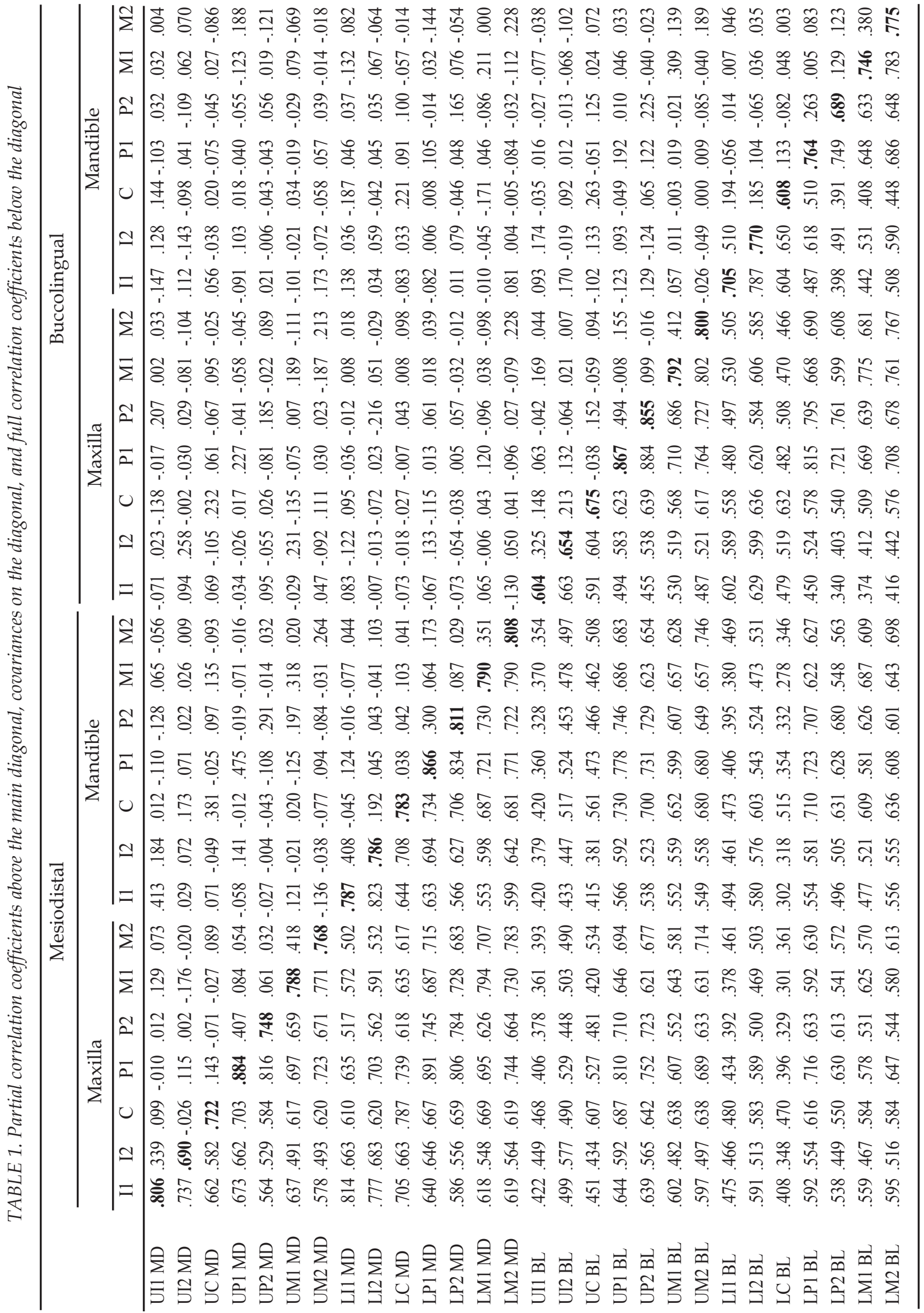


collectively, account for most of the variability in this data set in the statistical sense. Variance components of the six factors tested here are expressed as percentages of the explained variance (Table 2).

\section{Caveat}

Partitioning total phenotypic variance into the relative fractions due to the six sources (listed above) is done to disclose differences in the relative contributions of these contributors to anatomic variation. So, for example, variations among the four tooth types $(58.8 \%$ of total) is found to be enormously greater than variations between the MD and BL crown diameters at 2.5\% (i.e., between the two conventional axes used to reflect size
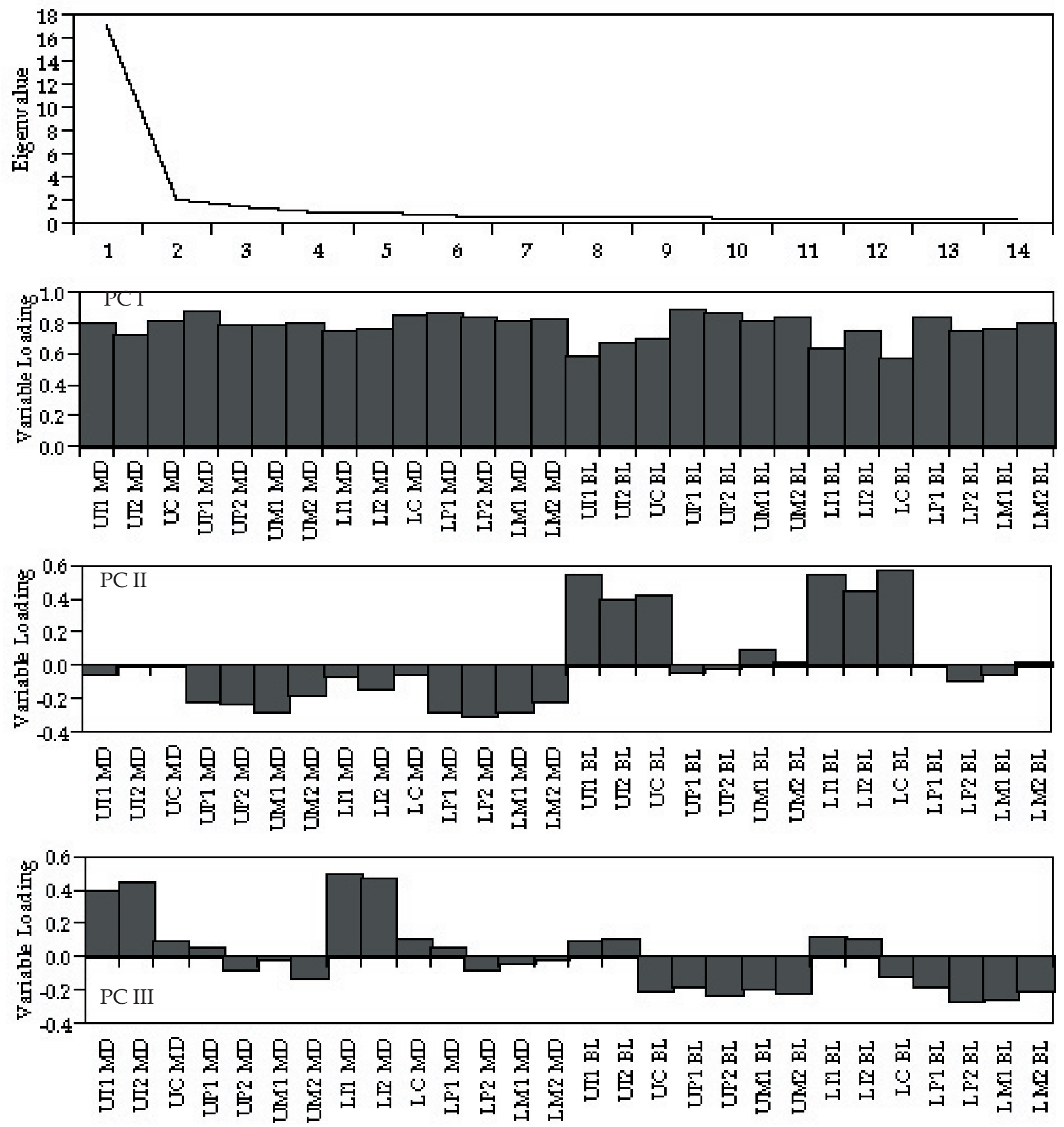

Fig. 1. Results of principal components analysis on the 200 cases in the present study ( 28 crown dimensions). Top: Distribution of eigenvalues showing how most of the variation is in the first canonical component and how quickly the subsequent values descend, so that just the first three are larger than 1.0. The other three panels are graphs of the variables' weights on each of the three principal components. 
variation). Whether large or small, these components do not address whether there are statistically significant differences between groups within one of these six canonical dimensions. For example, the smallest source of variation in the present analysis is "position" - whether a tooth is the mesial, stable tooth or the distal, variable tooth within a morphogenetic field (I, P, M). Even though position only accounts for $0.4 \%$ of the total variance, there still are highly significant statistical differences in mean size and in variance between mesial and distal teeth within a field (Kieser, 1990). Consequently, these two issues (source of variation versus statistical significance) are unrelated issues.

\section{Tooth type}

By far, the largest variance component $(82.8 \%)$ is tooth type, namely whether the tooth is an incisor, canine, premolar, or molar (Fig. 3). This finding has an intuitive appeal because heterodonty - the segmentation of the dentition into functionally specialized tooth types (incisors for nipping, canines for piercing, premolars for trituration, and molars for crushing) - is the fundamental arrangement of the primate dentition (Todd, 1918; Butler 1939, 1956; Swindler, 2002). The other anatomic effects in the present analysis simply involve duplication within the fields: duplication across the upper and lower arch producing structurally similar antagonists; duplication of a distal tooth creating the short meristic series that Weiss (1990), Jernvall (2000; Jernvall and Jung 2000), and others point out is an efficient method of increasing the number of structures, essentially by duplicating existing ones. The other sort of duplication (not included here) is tied to the ontogeny of bilateral symmetry, where left and right paired structures develop, apparently using the same genetic information, symmetrically across the midline. It would seem, then, that the four morphogenetic fields (one for each tooth type) constitute the basic organizing theme-with most of the variation among fields - and that, within fields, teeth enumerated front-to-back (the "pole" and the "variable" tooth; Dahlberg, 1945, 1951), side-to-side (bilateral symmetry), and craniocaudally (creating analogous tooth morphologies in the two jaws) consume comparatively

TABLE 2. Estimates of the proportion of variance for each of the 7 parameters in the model

\begin{tabular}{lcc}
\hline \multicolumn{1}{c}{ Source } & Estimate & Percentage \\
\hline Tooth Type & 2.47247 & 58.76 \\
Arcade & 0.20484 & 4.87 \\
Race & 0.14707 & 3.49 \\
Dimension & 0.10735 & 2.55 \\
Sex & 0.03633 & 0.86 \\
Position & 0.01656 & 0.39 \\
Residual & 0.83461 & 19.84 \\
Total & & 100.00 \\
\hline
\end{tabular}

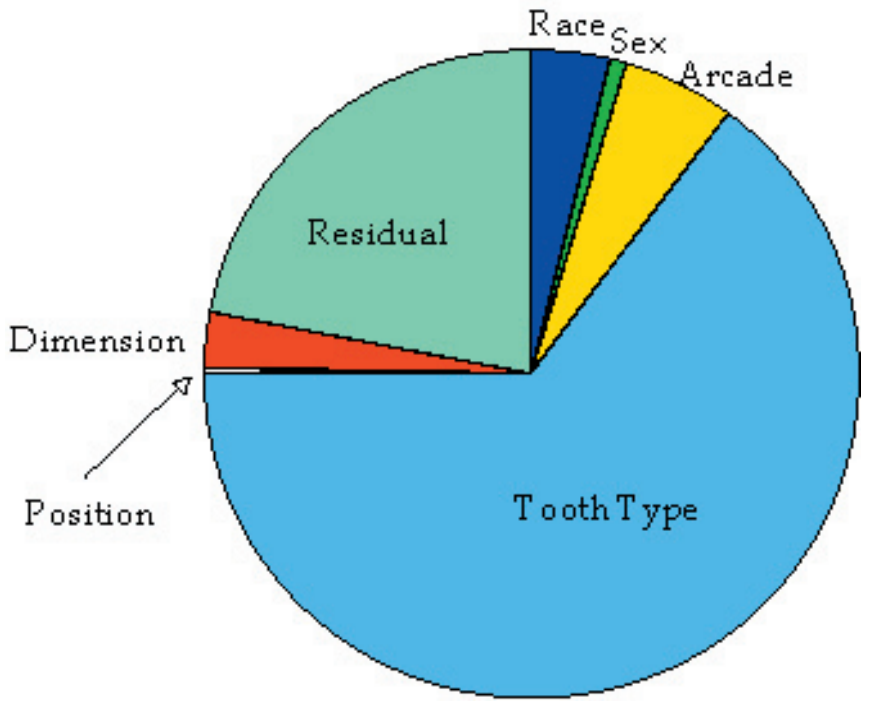

Fig. 2. Pie chart showing the apportionment of tooth size variation based on the six variables in the model (see text for details).

little variation. In a practical sense, this large variance due to tooth type implies that dental anthropologists commonly will want to include variables from all tooth types (I, C, P, M) rather than multiple measurements within a tooth type, since tooth type is the canonical axis of variation.

\section{Arcade}

While it is a distant second in terms of absolute variance, arcade (Fig. 4) counts for the next-largest component of variance $(6.9 \%)$, which is in concert with the results of factor analysis of dental metrics showing that, aside from an overall size effect, most factors or principal components (i.e., intercorrelated multivariable dimensions of teeth) typically are arcade-specific (e.g., Potter et al., 1968; Brown and Townsend, 1979). Perhaps this has been shown most clearly by Potter et al. (1976) who characterized the few axes of genetic variation in the dentition. One genetic factor was bilateral sym-

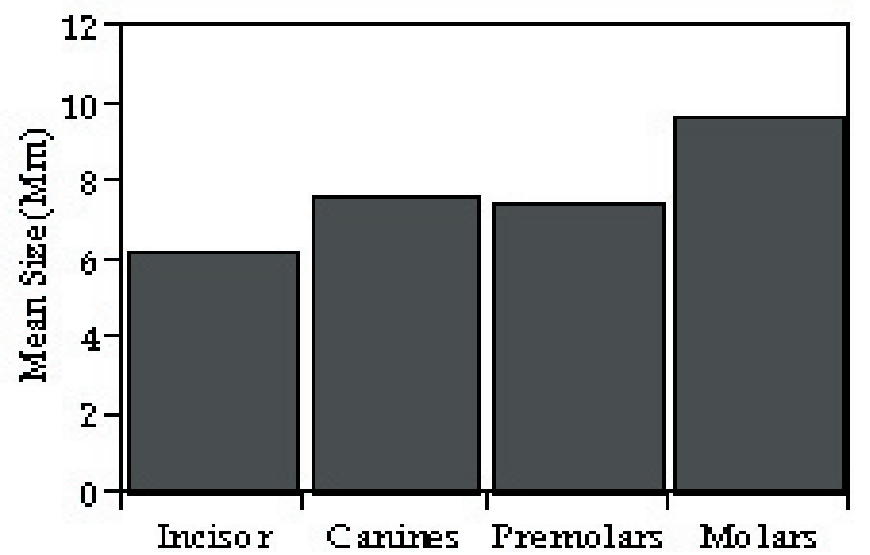

Fig. 3. Graph of mean tooth size by tooth type. 
metry; every genetic factor identified for a dimension on one side included the antimeric dimension on the other. Secondly, Potter disclosed a buccolingual crown size factor that extended throughout the maxillary (but not the mandibular) teeth. Thirdly, a genetic factor influenced both MD and BL dimensions of the mandibular anterior teeth. It is noteworthy that these genetic factors control regions of the dentition, not specific teeth. Recent computer modeling (Salazar-Ciudad and Jernvall, 2002) shows comparable results, namely that controlling just a few parameters can account for both the ontogenetic and phylogenetic variations within and among tooth types, both metrically and morphologically.

In the present study, Figure 4 displays the arcade differences graphed across the 14 tooth crown dimensions.

\section{Race}

The estimate of variance for "race" in this study might be criticized because only two groups were included and because American blacks and whites have experienced several generations of low level gene flow, primarily from whites to blacks (literature reviewed in Pollitzer, 1999).

On the other hand, Subsaharan Africans and Ameri- can whites are at either end of the contemporary spectrum of human tooth sizes (Harris and Rathbun, 1991), except of course for the megadont native Australians (e.g., Smith et al., 1981). Odontometric studies of American blacks and whites routinely find that blacks possess significantly larger teeth (Richardson and Malhotra, 1975; Macko et al., 1979; Vaughan and Harris, 1992). In the future, it may be informative to increase the mix of ethnic samples in this assessment of the sources of tooth size variation.

The critical issue, however, is recognition of the small component of variance attributable to the black-white difference, estimated here at $3.5 \%$ (Fig. 5). The minor contribution of "race" is no longer surprising (Lewontin, 1972), but these data are confirmatory, using quite a different tissue system, that races have been defined historically using very superficial criteria, whereas the great preponderance of variation is among individuals within groups, not among them.

\section{Dimension}

Dimension of the tooth crown - whether the crown is measured mesiodistally or buccolingually-accounted for $3.6 \%$ of the total variance. This is interesting because it shows that these geometrically orthogonal axes of a
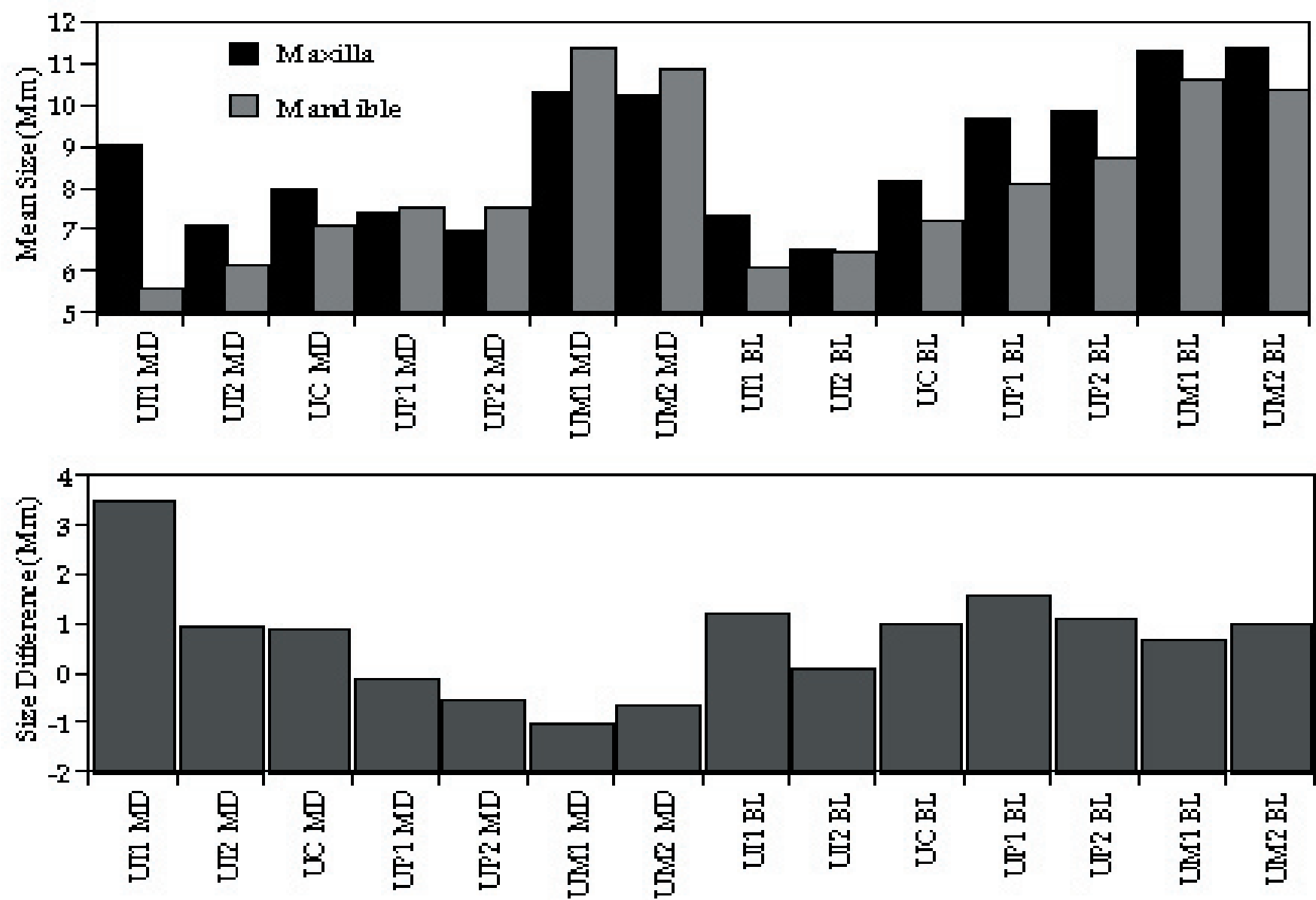

Fig. 4. Top: Graphs of the mean crown sizes by tooth and arcade and plot of the maxillary-minus-mandibular size differences (bottom). 

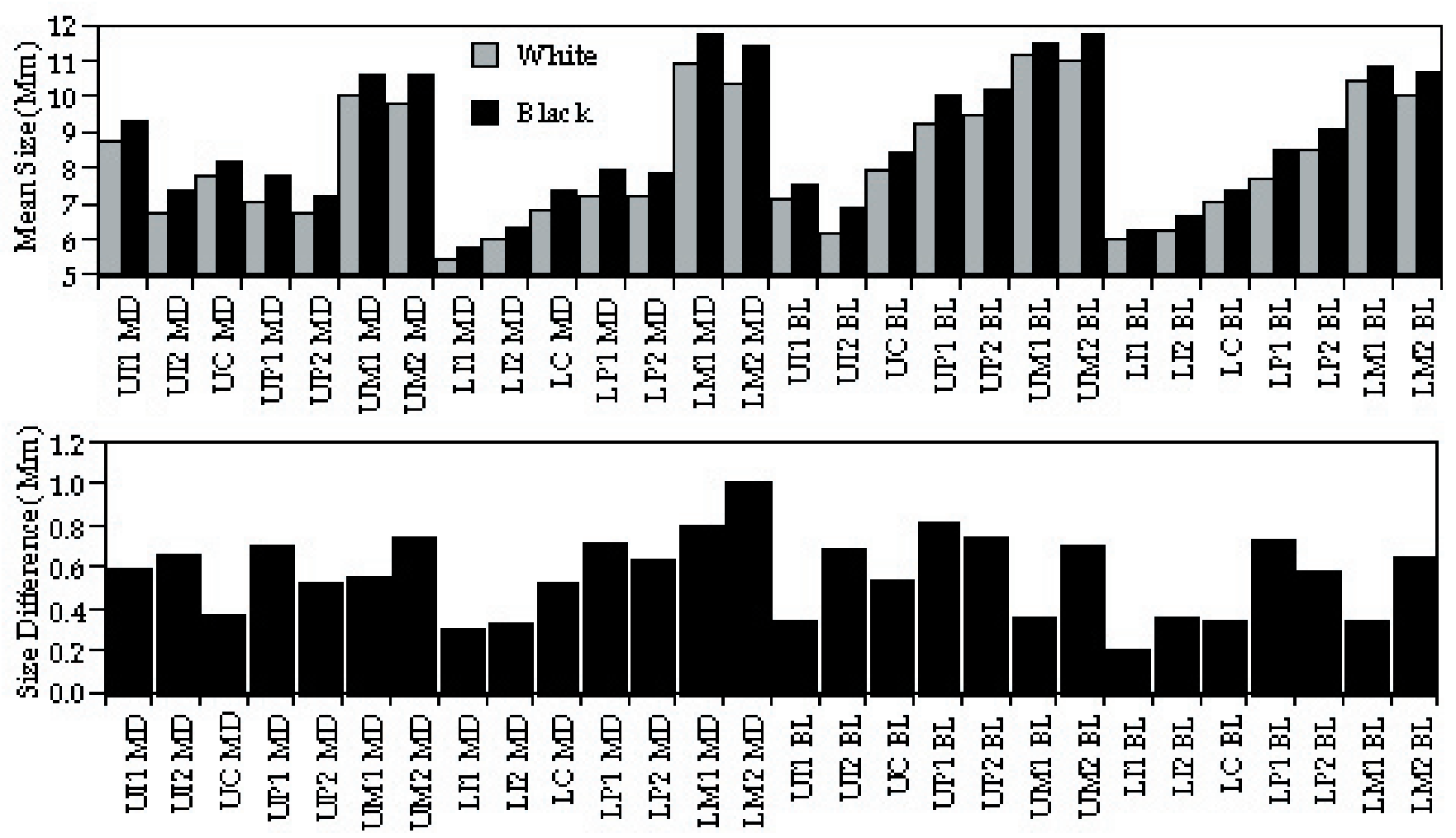

Fig. 5. Plot of crown dimensions by race (top) and black-minus-white differences in mean size showing that black have larger means throughout the dentition (bottom).

crown are largely coupled in terms of their ontogeny and genetic control. If these two commonly-measured axes of crown size (MD and BL) were not strongly related, one would expect appreciably more variance to be due to this contrast of measured dimensions. Researchers who have studied the genetic control of tooth size (e.g., Sofaer et al., 1971; Potter et al., 1976; Townsend and Brown, 1978) have commented on differences between MD and BL dimensions, but the results often are inconsistent among studies, suggesting that sampling fluctuations may be at work.

The suggestion has been advanced that MD dimensions have lower heritabilities than BL dimensions because teeth compete for size of the dental lamina in the dental arch. In contrast, BL dimensions do not. This scenario seems to be insufficient as concerns a couple of developmental points. Teeth do not develop from the dental lamina-like beads on a string-instead, they develop from projections of condensed mesenchyme (i.e., the presumptive dental papilla) that extend away from the presumptive occlusal plane, with considerable space between them (Arey, 1965; Slavkin, 1974; Ooë, 1981). The tooth buds develop in a three-dimensional array such that, while their bony crypts may overlap mesiodistally, they are offset mediolaterally and craniocaudally (van der Linden and Duterloo, 1976; Duterloo, 1991). Teeth do not compete for space until their fully formed crowns erupt into the oral cavity where underdeveloped arch size may cause an arch-size to tooth- size discrepancy (Little, 1975). The high prevalence of crowding in contemporary westernized populations is a recent epidemiological problem that seems to be predominately acquired rather than inherited (Corruccini and Potter, 1980; Harris and Smith, 1980).

\section{Sex}

It is well documented that males have bigger teeth than females as statistical averages (e.g., Mijsberg, 1931; Gonda, 1959; Garn, 1966; Garn et al. 1964, 1967; Harris and Bailit, 1987), though the amount of sex difference is specific to a population, not a fixed effect (Hanihara, 1978). It is a bit surprising, then, that variance due to sex accounted for just $1.2 \%$ of the total variation in the present study (Fig. 6). On the other hand, humans are characterized by their trivial sexual dimorphism in tooth size compared to the great apes (e.g., Harvey et al., 1978; Swindler, 2002). Garn et al. (1967) showed that the canine was the most dimorphic tooth in humans, at 4-6\% depending on the group studied, which pales against such nonhuman primates as Papio and Pan, where the canine is more than half again as large in males as in females. The issue should also be considered that univariate analysis tends to exaggerate sex differences because redundant male-female differences are included in each test (Potter, 1972).

Ditch and Rose (1972) used discriminant functions analysis to correctly determine sex in an average of 
93\% of their cases (depending on the set of variables analyzed), and Garn and coworkers (1977, 1978) arrived at similar success rates. Brown and Townsend (1979) reported lower correct allocations (ca. 75\% or less) using data from aboriginal Australians - the same as reported by Hanihara (1979) - indicating that the degree of sexual dimorphism is not tied to the tooth sizes of a group per se.

In passing, researchers also have provided discriminant functions based on crown sizes of the primary teeth that correctly identify sex better than expected from chance (DeVito and Saunders, 1990; Tsutsumi et al., 1993) even though the primary teeth are much less dimorphic (Harris, 2001).

\section{Position}

Depending on their position within a morphogenetic field (I, P, M), teeth are labeled as "stable" or "variable" (Butler, 1939; Dahlberg, 1945). This dichotomy refers to the metric and morphological variation exhibited by a tooth. A stable, early-forming tooth is larger, possesses more and larger cusps and other crown features, and is less likely to be reduced in size or congenitally absent. These and other considerations led Dahlberg (1945, 1951, 1986) and others to characterize the "fields" of the human dentition (Fig. 7). Several studies have shown that the increased variability of distal "variable" teeth is due to diminished genetic control (e.g., Lundström, 1948; Alvesalo and Tigerstedt, 1974).

(As an aside, this study did not account for the apparent field reversal, where LI1 is more variable than LI2, which Kjaer (1980) attributes to the weak vascular supply in the mandibular midline because of the symphysis menti.)

The present study shows that position is a comparatively small axis of variation, estimated at $0.4 \%$, making it the most trivial of the factors studied in this model. This also emphasizes the caveat (above) that estimating the relative sources of variation in the dentition is a different issue than whether particular teeth exhibit statistically significant differences. A key metrical attribute of a pole tooth within a field is its relative metric stability (Townsend and Brown, 1981). Coefficients of variation are graphed in Figure 8, where it is seen that it is not a foregone conclusion that the later-forming tooth possesses significantly great variance statistically. For the six contrasts in Figure 8, just three achieved significance ( $\alpha=0.05$ for one-tail tests). Just the maxillary incisors (I2 $>$ I1) and the upper and lower molars (M2 > M1) exhibit significantly more variance in one tooth vis-à-vis the other. In all these instances, the distal tooth is always the more variable tooth.
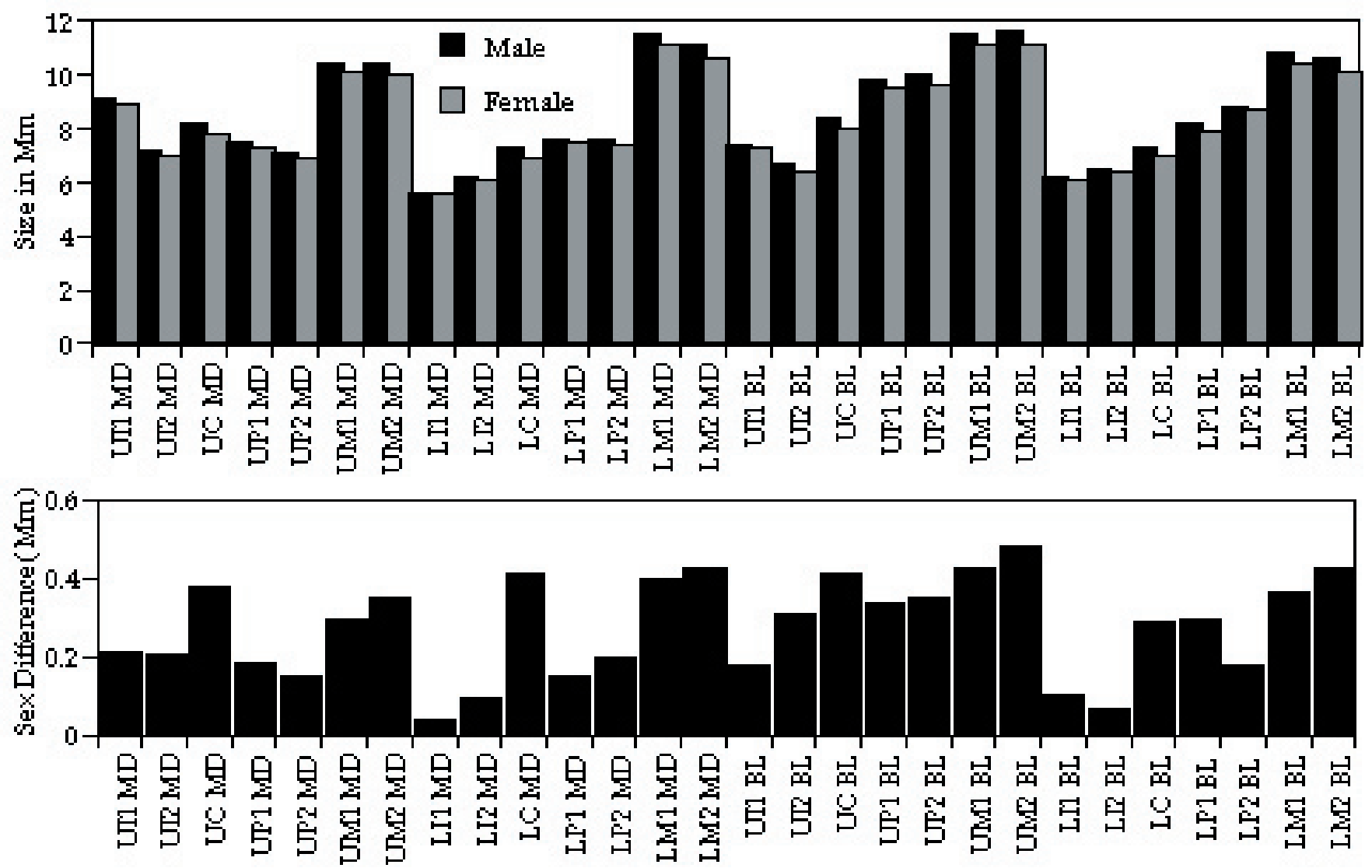

Fig. 6. Plot of tooth crown dimensions by sex (top) and plot of the male-minus-female differences (bottom) showing that, characteristically, males have larger mean crown dimensions. 


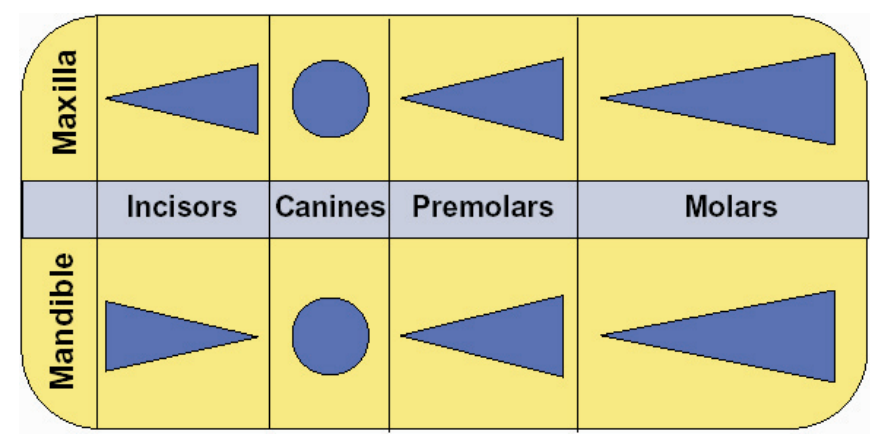

Fig. 7. Diagrammatic depiction of the morphogenetic fields in the human permanent dentition (modified from Dahlberg, 1951). The vertical height of the triangles reflects the variability of the distal tooth in each field. The exception is the 'reversed' field in the mandibular incisor region where the central incisor is more variable. There a mesial-to-distal gradient of increasing metric and morphological variation in the other fields (the stable canine obviously has but one tooth in each quadrant).

\section{OVERVIEW}

What are the major axes of variation in the permanent dentition in terms of tooth size? Results of the present study show that the canonical axis is among tooth types, which accounts for more than half of the variation (59\%). There is a dramatic drop-off after tooth type is accounted for. Arcade $(4.9 \%)$, race $(3.5 \%)$, and crown dimension $(2.6 \%)$ have only minor but comparatively intermediate values. Least influential are sex $(0.9 \%)$ and tooth position within a field $(0.4 \%)$. None of these axes of variation hinges on any one tooth, and the fundamental lack of more and more-prominent axes of variation is assumed to be due to the strong, pervasive statistical and developmental correlations among crown dimensions.

\section{LITERATURE CITED}

Alvesalo L, Tigerstedt PMA. 1974. Heritabilities of human tooth dimensions. Hereditas 77:311-318.

Arey LB. 1965. Developmental anatomy: a textbook and laboratory manual of embryology. Philadelphia: WB Saunders Company.

Avery JK, ed. 1994. Oral development and histology, 2nd ed. New York: Thieme Medical Publishers, Inc.

Bateson W. 1894. Materials for the study of variation: treated with special regard to discontinuity in the origin of species. London: Methuen.

Black TK. 1979. Dental wear and dental metrics. Am J Phys Anthropol 50:419-420 (abstract).

Brown T, Townsend GC. 1979. Sex determination by single and multiple tooth measurements. Occas Papers Hum Biol 1:1-16.

Butler PM. 1939. Studies of the mammalian dentition: differentiation of the postcanine dentition. Proc Zool Soc, London 109B:1-36.

Butler PM. 1956. The ontogeny of molar pattern. Biol Rev 31:30-70.

Butler PM. 2001. What happened to the field theory. In: Brook A, editor. Dental morphology 2001. Sheffield: Sheffield Academic press, p 3-12.

Coon CS. 1965. The living races of man. New York: Alfred A. Knopf.

Corruccini RS. 1977. Crown component variation in hominoid lower third molars. Z Morph Anthrop 68:14-25.

Corruccini RS. 1978. Crown component variation in hominoid upper first premolars. Arch Oral Biol 23:494-494.

Corruccini RS, Potter RH. 1980. Genetic analysis of occlusal variation in twins. Am J Orthod 78:140-154.

Dahlberg AA. 1945. The changing dentition of man. J Am Dent Assoc 32:676-690.

Dahlberg AA. 1951. The dentition of the American Indian. In: Laughlin WS, editor. The physical anthropology of the American Indian. New York: Viking Fund Inc, p 138-176.

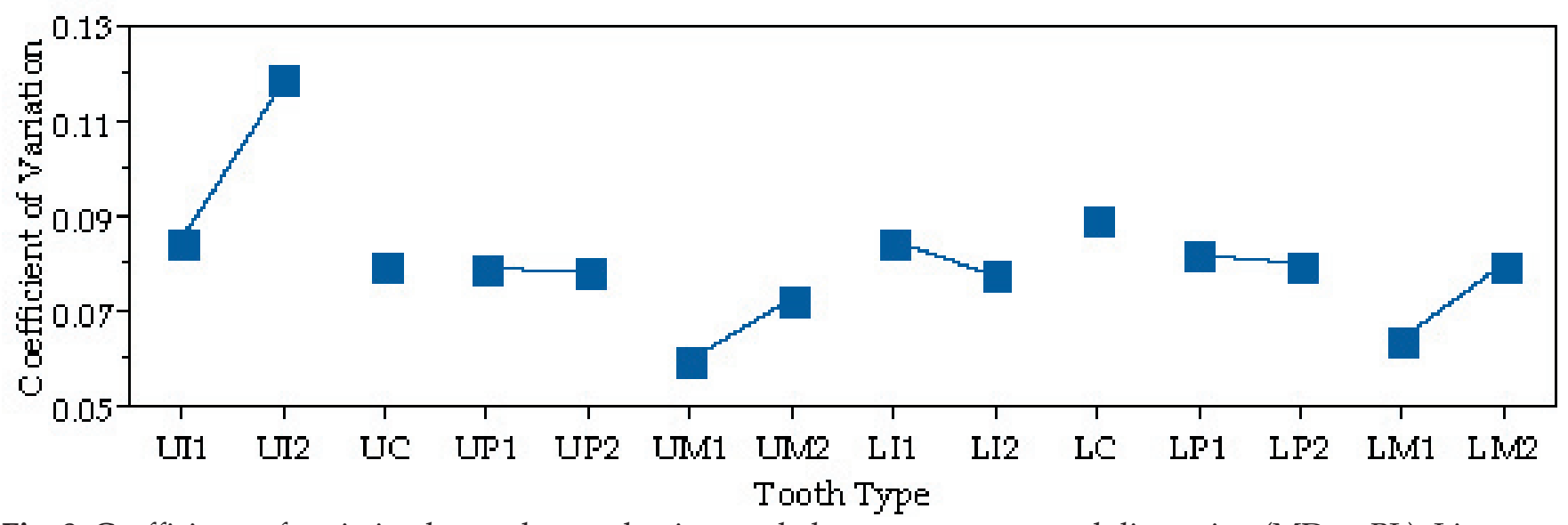

Fig. 8. Coefficients of variation by tooth type, having pooled across race, sex, and dimension (MD or BL). Line segments connect the stable and variable tooth within each morphogenetic field, but just three of the six comparisons disclose the anticipated mesial-to-distal increase in variability, namely UI1-to-UI2, UM1-to-UM2, and LM1-to-LM2. 
Dahlberg AA. 1986. Ontogeny and dental genetics in forensic problems. Forensic Sci Int 30:163-176.

Davenport CB. 1927. Guide to physical anthropometry and anthroposcopy. Eugenics Research Association Handbook Series, No. 1. New York: Cold Spring Harbor.

DeVito C, Saunders SR. 1990. A discriminant function analysis of deciduous teeth to determine sex. J Foren Sci 35:845-858.

Ditch LE, Rose JC. 1972. A multivariate dental sexing technique. Am J Phys Anthropol 37:61-64.

Duterloo HS. 1991. An atlas of dentition in childhood: orthodontic diagnosis and panoramic radiology. Aylesbury, England: Wolfe Publishing Ltd.

Falconer DS. 1989. Introduction to quantitative genetics, 3rd ed. New York: John Wiley \& Sons, Inc.

Falk D, Corruccini RS. 1982. Efficacy of cranial versus dental measurements for separating human populations. Am J Phys Anthropol 57:123-127.

FitzGerald C, Hillson S. 2002. Dental reduction in late Pleistocene and early Holocene hominids. Am J Phys Anthropol suppl 34:70 (abstract).

Garn SM, Cole PE, Van Alstine WL. 1978. Sex discriminatory effectiveness using combinations of root lengths and crown diameters. Am J Phys Anthropol 50:115-118.

Garn SM, Cole PE, Wainright RL, Guire KE. 1977. Sex discriminatory effectiveness using combinations of permanent teeth. J Dent Res 56:697.

Garn SM, Lewis AB, Kerewsky RS. 1965. Interrelationships of the mesial and distal teeth. J Dent Res 44:350-354.

Garn SM, Lewis AB, Kerewsky RS. 1968. Relationship between buccolingual and mesiodistal tooth diameters. J Dent Res 47:495.

Gonda K. 1959. On the sexual difference in the dimensions of human teeth. J Anthropol Soc Nippon 67:151-163.

Green J. 2002. Morphogen gradients, positional information, and Xenopus: interplay of theory and experiment. Dev Dyn 225:391-408.

Gregory WK. 1934. Polyisomerism and anisomerism in cranial and dental evolution among vertebrates. Proc Natl Acad Sci 20:1-9.

Hanihara K. 1978. Differences in sexual dimorphism in dental morphology among several human populations. In: Butler PM, Joysey KA, editors. Development, function and evolution of teeth. London: Academic Press, p 127-134.

Harris EF. 2001. Deciduous tooth size distributions in recent humans: a world-wide survey. In: Brook A, editor. Dental morphology 2001. Sheffield, England: Sheffield Academic Press, p 13-30.

Harris EF, Bailit HL. 1987. Odontometric comparisons among Solomon Islanders and other Oceanic peoples. In: Friedlaender JS, editor. The Solomon Islands Project: a long term study of health, human biology and culture change. Cambridge: Oxford University Press, p 215264.

Harris EF, Bailit HL 1988. A principal components analysis of human odontometrics. Am J Phys Anthropol 75:87-
99.

Harris EF, Rathbun TA. 1991. Ethnic differences in the apportionment of tooth sizes. In: Kelley MA, Larsen CS, editors. Advances in dental anthropology. New York: Alan R. Liss, Inc., p 121-142.

Harris EF, Smith RJ. 1980. A study of occlusion and arch widths in families. Am J Orthod 78:155-163.

Hartley HO, Rao JNK, LaMotte L. 1978. A simple synthesisbased method of variance component estimation. Biometrics 34:233-244.

Harvey PH, Kavanagh M, Clutton-Brock TH. 1978. Sexual dimorphism in primate teeth. J Zool 186:475-485.

Henderson AM. 1975. Dental field theory: an application to primate dental evolution. Ph.D. dissertation, University of Colorado, Boulder.

Hillson S. 1996. Dental anthropology. Cambridge: Cambridge University Press.

Jernvall J. 2000. Linking development with generation of novelty in mammalian teeth. Proc Natl Acad Sci 97: 2641-2645.

Jernvall J, Jung HS. 2000. Genotype, phenotype, and developmental biology of molar tooth characters. Yrbk Phys Anthropol 43:171-190.

Jernvall J, Thesleff I. 2000. Reiterative signaling and patterning during mammalian tooth morphogenesis. Mech Dev 92:19-29.

Kieser JA. 1990. Human adult odontometrics: the study of variation in adult tooth size. Cambridge: Cambridge University Press.

Kjaer I. 1980. Development of deciduous mandibular incisors related to developmental stages in the mandible. Acta Odontol Scand 38:257-262.

Lewontin RC. 1972. The apportionment of human diversity. In Dobzhansky T, Hecht T, and Steere WC, editors. Evol Biol, vol 6, p 381-398.

Lundström A. 1948. Tooth size and occlusion in twins. New York: Karger.

Little RM. 1975. The irregularity index: a quantitative score of mandibular anterior alignment. Am J Orthod 68:554563.

Macko DJ, Ferguson FS, Sonnenberg EM. 1979. Mesiodistal crown dimensions of permanent teeth of Black Americans. J Dent Child 46:42-46.

Martin R. 1928. Lehrbuch der Anthropologie in systematischer Dartellung. Jena: Gustav Fischer.

Mijsberg WA. 1931. On sexual differences in the teeth of Japanese. Koninklijke Akademie voor Wetenschap 34: 1111-1115.

Moorrees CFA, Reed RB. 1964. Correlations among crown diameters of human teeth. Arch Oral Biol 9:685-697.

Moyers RE. 1988. Handbook of orthodontics, 4th ed. Chicago: Year Book Medical Publishers, Inc.

Ooë T. 1981. Human tooth and dental arch development. Tokyo: Ishiyaku Publishers, Inc.

Pollitzer WS. 1999. The Gullah people and their African heritage. Athens: University of Georgia Press.

Potter RHY. 1971. Univariate versus multivariate differences 
in tooth size according to sex. J Dent Res 51:716-722.

Potter RHY, Nance WE. 1976. A twin study of dental dimension. I. Discordance, asymmetry and mirror imagery. Am J Phys Anthropol 44:391-396.

Potter RHY, Nance WE, Yu P, Davis WB. 1976. A twin study of dental dimensions. II. Independent genetic determinants. Am J Phys Anthropol 44:397-412.

Potter RH, Yu PL, Dahlberg AA, Merritt AD, Conneally PM. 1968. Genetic structure of tooth size factors in size factors in Pima Indian families. Am J Hum Genet 20: 89-100.

Richardson ER, Malhotra SK. 1975. Mesiodistal crown dimension of the permanent dentition of American Negroes. Am JOrthod 68:157-164.

Salazar-Ciudad I, Jernvall J. 2002. A gene network model accounting for development and evolution of mammalian teeth. Proc Natl Acad Sci 99:8116-8120.

Selmer-Olson R. 1949. An odontometrical study of the Norwegian Lapps. Skrifter utgitt av det Norske Videnskaps-Akademi Oslo, I. Mat-Naturv-Klasse, No. 3.

Slavkin HC. 1974. Embryonic tooth formation: a tool for developmental biology. Oral Sci Rev p 6-136.

Smith P, Brown T, Wood WB. 1981. Tooth size and morphology in a recent Australian Aboriginal population from Broadbeach, South East Queensland. Am J Phys Anthropol 55:423-432.

Sofaer JA, Bailit HL, MacLean CJ. 1971. A developmental basis for differential tooth reduction during hominid evolution. Evolution 25:509-517.

\section{Decoding Your Subscription}

Want to know when your subscription to Dental Anthropology expires? Membership in the Association and, thus, your subscription to Dental Anthropology is on an annual basis coinciding with the calendar year. Have a look at the mailing label on the evelope that this issue arrived in, and you will see the year for which your dues have been paid. The year is located in parentheses to the right of your name. So, if the mailing label says " (2003)" you are paid to the end of this calendar year.

In order to extend your membership, fill-out the relevant portions of the enclosed form-remember to include appropriate payment - and mail it to the Secretary-Treasurer of the Association:
Dr. Heather H. Edgar
Maxwell Museum of Anthropology
MSC01 1050
1 University of New Mexico
Albuquerque, New Mexico 87131-0001 USA
telephone: (505) 277-4415
e-mail: hjhedgar@unm.edu

Solow B. 1966. The pattern of craniofacial associations. Acta Odont Scand 24:suppl 46.

Swindler DR. 2002. Primate dentition: an introduction to the teeth of non-human primates. Cambridge: Cambridge University Press.

Tanaka MM, Johnston LE. 1974. The prediction of the size of unerupted canines and premolars in a contemporary orthodontic population. J Am Dent Assoc 88:798-801.

Todd TW. 1918. An introduction to the mammalian dentition. St Louis: CV Mosby Company.

Townsend GC. 1976. Tooth Size Variability in Australian Aboriginals: A Descriptive and Genetic Study. Ph.D. dissertation, University of Adelaide, South Australia.

Townsend GC, Brown T. Morphogenetic fields within the dentition. Aust Orthod J 1981;7:3-12.

Tsutsumi H, Matsui N, Morita Y, Sano E, Okamura K, Komura T, Takei T. 1993. [Sex determination with a discriminant function analysis of deciduous teeth size in plaster models.] Nippon Hoigaku Zasshi 47:466-480.

van der Linden FPGM, Duterloo HS. 1976. Development of the human dentition - an atlas. Hagerstown: Harper and Row.

Vaughan ME, Harris EF. 1992. Deciduous tooth size standards for American Blacks. J Tenn Dent Assoc 72: 30-33.

Weiss KM. 1990. Duplication with variation: metameric logic in evolution from genes to morphology. Yrbk Phys Anthropol 33:1-24.

Yamaguchi TP. 1997. New insights into segmentation and patterning during vertebrate somitogenesis. Curr Opin Genet Dev 7:513-518.

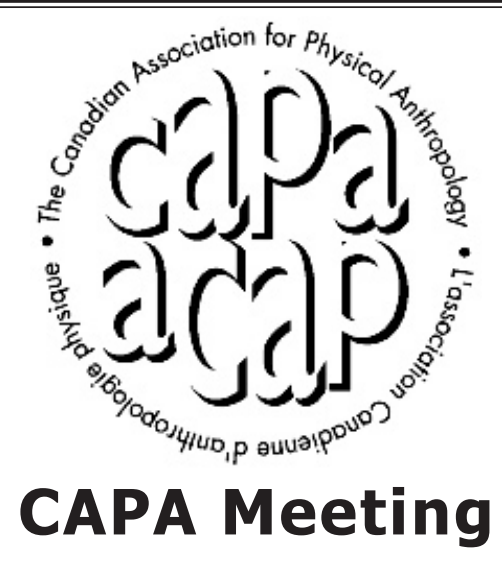

The annual meeting of the Canadian Association for Physical Anthropology will be held in Edmonton, Alberta, October 23-25 of 2003. Contributed papers and posters for a symposium on Dental Anthropology are welcome.

For further information, contact Dr. Nancy Lovell, Department of Anthropology, University of Alberta, Edmonton, T6G 2H4 Canada. E-mail: nancy.lovell@ualberta.ca 